\title{
Disturbance of Response to Acute Thermal Pain in Naturally Occurring Cholecystokinin-A Receptor Gene Knockout Otsuka Long-Evans Tokushima Fatty (OLETF) Rats
}

\author{
Kyoko Miyasaka ${ }^{1, *}$, Shigeki Nomoto ${ }^{2}$, Minoru Ohta ${ }^{1}$, Setsuko Kanai ${ }^{1}$, Takao Kaneko ${ }^{3}$, Shoichi Tahara ${ }^{3}$, \\ and Akihiro Funakoshi ${ }^{4}$ \\ ${ }^{1}$ Department of Clinical Physiology, ${ }^{2}$ Department of Motor and Autonomic Nervous System Integration, \\ ${ }^{3}$ Redox Regulation Research Group, Tokyo Metropolitan Institute of Gerontology, Tokyo 173-0015, Japan \\ ${ }^{4}$ Department of Gastroenterology, Kyushu Cancer Center, Fukuoka 811-1395, Japan
}

Received March 1, 2006; Accepted June 7, 2006

\begin{abstract}
Otsuka Long-Evans Tokushima Fatty (OLETF) rats lack cholecystokinin-A receptor (CCK-AR) because of a genetic abnormality. We observed that body temperature homeostasis in response to changes in ambient temperature was deteriorated in OLETF rats, while the functions of the signal outputs from the hypothalamus to effectors were not impaired. Deteriorated homeostasis was also seen in CCK-AR deficient (-/-) mice. In the present study, we examined whether the sensory pathway involved in transmitting signals about temperature from the skin to the brain was impaired in OLETF rats. To elucidate the involvement of CCK-AR function, we conducted the same experiment in CCK-AR(-/-) mice. Responses to thermal pain were assessed using the Hargreaves' plantar test apparatus. Shortening of withdrawal latency was observed in OLETF rats compared to control rats, indicating thermal hyperalgesia. Behavioral responses following paw withdrawal were disturbed in OLETF rats. The 5-hydroxytryptamine (5-HT) and 5 -hydroxyindole acetic acid contents in the hippocampus and frontal cortex of OLETF rats were significantly higher than in those of the controls. CCK-AR(-/-) mice did not show any differences from wild-type mice. In conclusion, OLETF rats showed thermal hyperalgesia and disturbed responses to thermal pain, and an alteration of 5-HT function might have a role in this disturbance.
\end{abstract}

Keywords: thermal pain, plantar test, knockout mouse, 5-hydroxytryptamine, Otsuka Long-Evans Tokushima Fatty (OLETF) rat

\section{Introduction}

Cholecystokinin (CCK) has been established as the most abundant neuropeptides in the mammalian brain (1). CCK-ergic systems influence various autonomic and behavioral functions of the mammalian body, including ingestive behavior, general activity, and the control of body temperature $(2-5)$. Two types of CCK receptors (CCK-AR and CCK-BR) have been cloned (5). In the brain, CCK-ARs are present only in certain regions, including the hippocampus, nucleus tractus solitarius,

*Corresponding author. miyasaka@tmig.or.jp

Published online in J-STAGE: August 5, 2006

doi: 10.1254/jphs.FP0060300 posterior nucleus accumbens, ventral tegmental area, substantia nigra, hypothalamus, and raphe nucleus, whereas CCK-BRs are distributed widely throughout the central nervous system $(6-9)$.

We $(10,11)$ previously found that Otsuka Long-Evans Tokushima Fatty (OLETF) rats, developed as a model of non-insulin-dependent diabetes mellitus (NIDDM) (12), lack CCK-AR because of a genetic abnormality. The CCK-AR gene of rats is approximately $10 \mathrm{~kb}$ in length and consists of five exons (13). Two exons, including the promoter area, are missing in OLETF rats; this strain has a 6847 base pair deletion of the CCK-AR gene (11). OLETF rats have revealed several abnormal functions, including a decrease in exploratory behavior (14), increase in anxiety (15), hyperphagia (10), impaired 
learning (16), and impaired endocrine and exocrine pancreatic functions $(17,18)$. However, these abnormalities were not always observed in CCK-AR deficient $(-/-)$ mice $(19-21)$, probably in part because of species differences.

Recently, we found in both OLETF rats and CCK$\mathrm{AR}(-/-)$ mice (3) that body temperature homeostasis in response to changes in ambient temperature $\left(0^{\circ} \mathrm{C}-\right.$ $30^{\circ} \mathrm{C}$ ) was deteriorated. As the responses of the anterior hypothalamic region to warming or cooling did not differ between OLETF and their normal counterpart, Long-Evans Tokushima (LETO) rats, the functions of the signal outputs from the hypothalamus to effectors in OLETF rats were not impaired. Thus, OLETF rats seem to have a deficit in the system for detecting ambient temperature maybe due to a lack of CCK-AR because the CCK-AR has been known to be located on the sensory fibers such as vagal afferent nerves (22). In the present study, we examined whether the sensory pathway for transmitting the temperature signal from the skin to brain was impaired in OLETF rats.

Moreover, to examine whether CCK-AR function was involved, the same experiment was conducted in CCK-AR(-/-) mice (21). The amino acid sequence of rat CCK-BR is $48 \%$ identical to the rat CCK-AR (5), and the expression patterns of these receptors in the brain overlap $(5-8)$. Although several pharmacological studies have used CCK receptor antagonists $(5,9)$, cross-reactivity, in which substances that should react to CCK-AR also react to CCK-BR and vice versa, could not be excluded. To distinguish the functional role of CCK-AR from that of CCK-BR, we also used CCK$\mathrm{BR}(-/-)$ and CCK-AR(-/-)BR(-/-) mice. The progenitor strains were $\mathrm{C} 57 \mathrm{BL} / 6 \mathrm{~J}$ and more than seven generations of back-crossing were performed $(3,19,20)$. These mice are all viable and fertile into adulthood.

CCK coexists in the mesolimbic dopamine neurons, and CCK-AR mediates the release of dopamine in the nucleus accumbens $(2,5)$. In the case of 5-hydroxytryptamine (5-HT), serotonin neurons originate from the raphe nucleus where CCK-AR is located, and project to the whole brain, including the hippocampus and hypothalamus (23). Based on this information, we measured monoamine contents after completion of the plantar test in OLETF and LETO rats as well as CCK-AR(-/-) and wild-type mice.

\section{Materials and Methods}

The present experimental protocol was reviewed and approved by the appropriate committee of the Tokyo Metropolitan Institute of Gerontology. We are also obligated to follow the Guiding Principles for the
Care and Use of Laboratory Animals approved by The Japanese Pharmacological Society.

\section{Animals}

Male LETO and OLETF rats (4-week-old) were obtained from the Tokushima Research Institute of Otsuka Pharmaceutical Co., Ltd. (Tokushima). CCK$\mathrm{AR}(-/-), \mathrm{CCK}-\mathrm{BR}(-/-), \mathrm{CCK}-\mathrm{AR}(-/-) \mathrm{BR}(-/-)$ mice, and wild-type mice $[\mathrm{CCK}-\mathrm{AR}(+/+) \mathrm{BR}(+/+)]$ were maintained in our laboratory. The progenitor strains for these mice were C57BL/6J $(19-21)$.

Animals were fed commercial chow (CRF-1; Charles River Japan, Inc., Atsugi) and water ad libitum. They were maintained in a vivarium at the Tokyo Metropolitan Institute of Gerontology, in a controlled environment at $23 \pm 1^{\circ} \mathrm{C}$, under a 12 -h light / 12-h dark photocycle (on at 8:00, off at 20:00). Experiments were conducted in OLETF and LETO rats at 9 to 14 weeks (before the onset of NIDDM in OLETF rats). The mean body weights at $9-14$ weeks of age were $361.4 \pm 15.7 \mathrm{~g}$ (the mean \pm S.D.) for LETO rats and $428.6 \pm 15.6 \mathrm{~g}$ for OLETF rats. The mice were used at $6-10$-month-old. The mean body weights of the mice $(6-10$-month-old $)$ according to genotype ( $\mathrm{n}=8$ for each strain) were as follows: $35.1 \pm 2.7 \mathrm{~g}$ (mean \pm S.D.) for wild-type, $33.5 \pm$ $3.0 \mathrm{~g}$ for CCK-AR(-/-), $31.8 \pm 2.6 \mathrm{~g}$ for CCK-BR(-/-), and $27.5 \pm 4.5 \mathrm{~g}$ for CCK-AR(-/-)BR(-/-). The CCK$\mathrm{AR}(-/-) \mathrm{BR}(-/-)$ mice weighed significantly less than mice of the other genotypes.

\section{Hargreaves' plantar test}

The animals were handled for $5 \mathrm{~min} /$ day and were placed in the box for $10 \mathrm{~min} /$ day for one month prior to the test.

The Hargreaves' plantar test apparatus (Ugo Basile, Varese, Italy) was used (24). This test is a model of acute thermal pain. Animals were placed on a 2 -mm-thick glass floor, and a mobile infrared heat generator with an aperture of $10 \mathrm{~mm}$ in diameter was aimed at the animal's hind paw under the floor. When an animal felt pain and withdrew its paw, the power shut off. The latency to paw withdrawal was determined. Shortening of the latency indicated thermal hyperalgesia. The behaviors such as paw withdrawn alone, flinching, and licking, were recorded after the animals withdrew their paw. Three trials each for the right and left hind paws were performed. Additionally, the same experiments were repeated on day 7 and day 14 after the first experiments. Thus, 18 trials for one animal were conducted, and mean values were calculated.

\section{Monoamine contents in the brain \\ OLETF and LETO rats as well as CCK-AR(-/-)}


and wild-type mice were decapitated between 10:00 and 11:00. The hypothalamus, hippocampus, striatum, and frontal cerebral cortex were quickly removed and immediately weighed and homogenized in $0.2 \mathrm{M}$ perchloric acid containing $100 \mathrm{mM}$ EDTA on ice. After $30 \mathrm{~min}$, the samples were centrifuged at $20,000 \times \mathrm{g}$ for $15 \mathrm{~min}$. The supernatants were filtered using $0.45-\mathrm{mm}$ filter paper. The contents of dopamine and its metabolites [3,4-dihydroxyphenylacetic acid (DOPAC), homovanillic acid (HVA), and 3-methoxytyramine (3-MT)]; 5-HT and its metabolite [5-hydroxyindole acetic acid (5-HIAA)]; and noradrenaline and adrenaline and their metabolites (3-methoxy-4-hydroxyphenylglycol and normethanephrine) in the supernatant were measured using high performance liquid chromatography with electrochemical detection, as described in a previous report by Gamache et al. (25).

\section{Statistical analysis}

Results are given as the mean \pm S.E.M. and were analyzed using one-way analyses of variance (ANOVA), followed by determination of Fisher's Protected Least Significant Difference (PLSD).

\section{Results}

\section{Hargreaves' plantar test}

OLETF rats responded to the thermal pain more quickly than LETO rats. The mean values of latency were $6.006 \mathrm{~s}$ for LETO rats and $5.031 \mathrm{~s}$ for OLETF rats $(P<0.007)$ (Fig. 1). Then, the responses were divided to three patterns: paw withdrawn alone, flinching, or licking after paw withdrawal, and the respective latency was compared. In LETO rats, the increase in latency for paw withdrawal was as follows: paw withdrawn alone $(5.375 \pm 0.659 \mathrm{~s}$, the mean \pm S.D. $)<$ flinching after paw withdrawal $(6.445 \pm 1.080 \mathrm{~s})<$ licking after paw withdrawal $(6.851 \pm 1.317 \mathrm{~s})$. These values were significantly different (Fig. 2). In contrast, in OLETF rats, latency did not differ among the three patterns (Fig. 2).

On the other hand, there were no significant differences with respect to latency among four genotypes of mice $(\mathrm{F}[3,31]=0.59, P=0.63$; data not shown $)$.

\section{Monoamine contents in the brain}

The contents of dopamine and its metabolites in each brain region did not differ between OLETF and LETO rats. The contents of 5-HT and 5-HIAA and of the sum of 5-HT and 5-HIAA in the hippocampus and cerebral

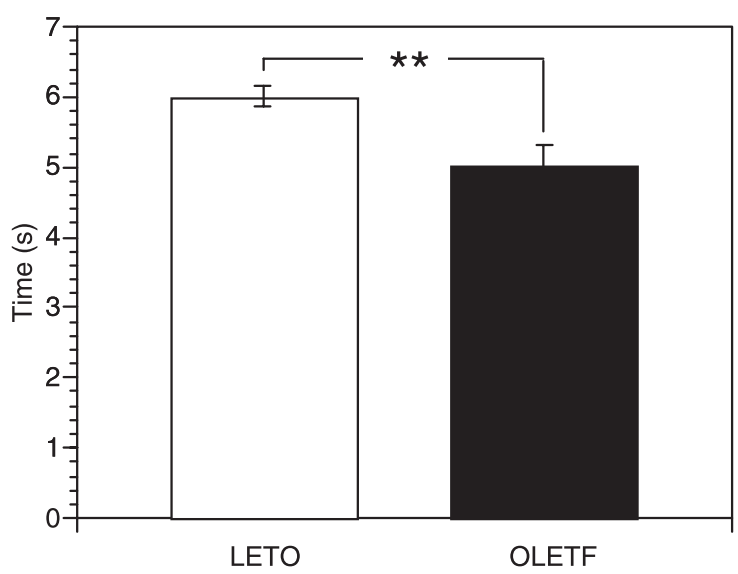

Fig. 1. Latency to paw withdrawal in response to thermal pain. The latency in OLETF rats was significantly shorter than that in LETO rats $(* * P<0.01)$.
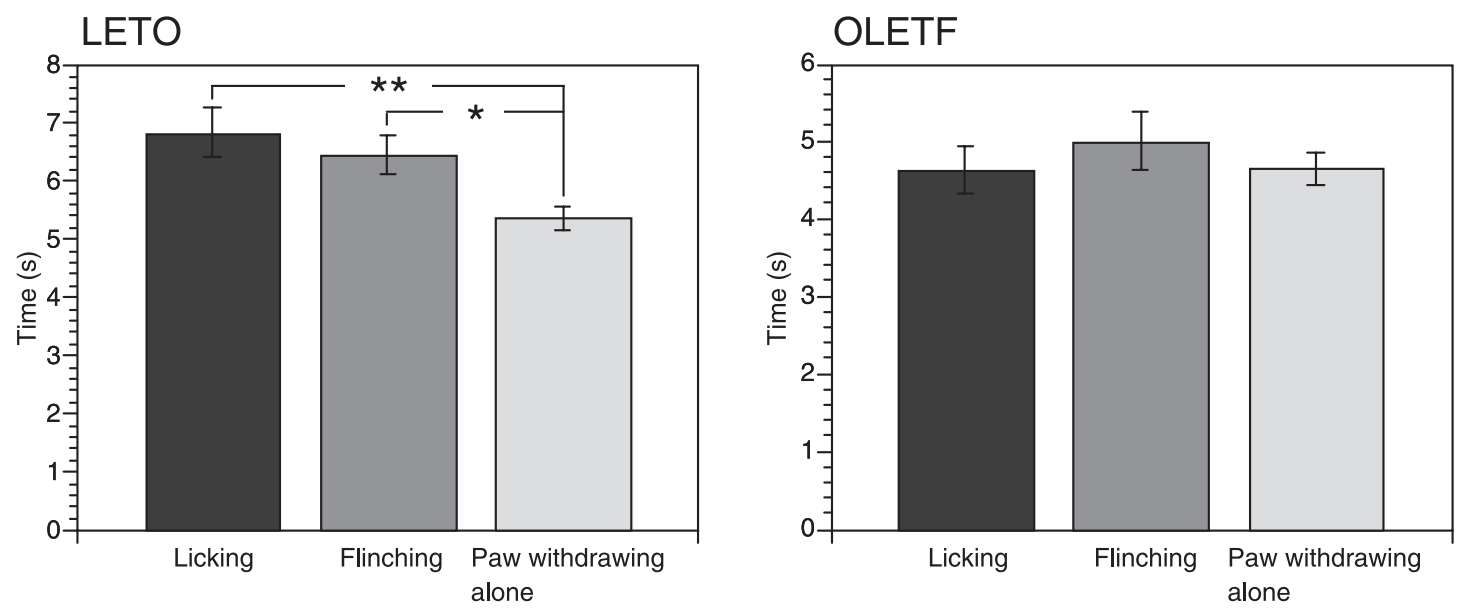

Fig. 2. Latencies to paw withdrawal alone, flinching, and licking. In LETO rats, the increase in latency to paw withdrawal alone $<$ flinching $<$ licking $[\mathrm{F}(2,27)=5.23, P=0.012]]$. In contrast, in OLETF rats, latency did not differ among the three patterns $[\mathrm{F}(2,26)=0.478, P=0.625] .{ }^{*} P<0.05$ and ${ }^{*} P<0.01$ by the multiple comparison test, $\mathrm{n}=9-10$ for each strain. 
Table 1. Concentrations of dopamine and 5-HT and their metabolites in the brain of OLETF and LETO rats ( $\mathrm{pmol} / \mathrm{mg}$ tissue)

\begin{tabular}{|c|c|c|c|}
\hline \multicolumn{4}{|l|}{ Brain region } \\
\hline \multirow[b]{2}{*}{ Strain } & \multirow{2}{*}{$\begin{array}{l}\text { Dopamine and } \\
\text { metabolites }\end{array}$} & \multicolumn{2}{|c|}{ 5-HT and 5-HIAA } \\
\hline & & 5-HT & 5-HIAA \\
\hline \multicolumn{4}{|l|}{ Striatum } \\
\hline LETO & $59.1 \pm 1.7$ & $0.29 \pm 0.02$ & $1.16 \pm 0.06$ \\
\hline OLETF & $54.9 \pm 2.7$ & $0.37 \pm 0.02 *$ & $0.99 \pm 0.15$ \\
\hline \multicolumn{4}{|c|}{ Hypothalamus } \\
\hline LETO & $1.69 \pm 0.17$ & $1.05 \pm 0.16$ & $2.58 \pm 0.48$ \\
\hline OLETF & $1.76 \pm 0.17$ & $1.17 \pm 0.09$ & $2.55 \pm 0.26$ \\
\hline \multicolumn{4}{|l|}{ Hippocampus } \\
\hline LETO & $0.54 \pm 0.07$ & $0.27 \pm 0.03$ & $0.89 \pm 0.14$ \\
\hline OLETF & $0.67 \pm 0.10$ & $0.69 \pm 0.04 *$ & $1.86 \pm 0.17^{*}$ \\
\hline \multicolumn{4}{|c|}{ Cerebral cortex } \\
\hline LETO & $0.92 \pm 0.16$ & $0.21 \pm 0.01$ & $0.39 \pm 0.07$ \\
\hline OLETF & $0.95 \pm 0.12$ & $0.46 \pm 0.07 *$ & $0.75 \pm 0.11 *$ \\
\hline
\end{tabular}

Values are the mean \pm S.E.M.; $n=4$ for LETO and $n=8$ for OLETF rats. The sums of dopamine, DOPAC, HVA, and 3-MT are shown. *Significantly higher than the respective values of LETO rats.

cortex were significantly higher in OLETF than in LETO rats (Table 1). The content of 5-HT in the striatum of OLETF was significantly higher than that of LETO rats, whereas the content of 5-HIAA did not differ between the strains.

In contrast, neither dopamine nor 5-HT differed in any brain region between CCK-AR(-/-) and wild-type mice (data not shown). The levels of noradrenaline and its metabolites were not different between OLETF and LETO rats or between CCK-AR(-/-) and wild-type mice (data not shown).

\section{Discussion}

The present study showed the thermal hyperalgesia in OLETF rats. In addition, OLETF rats showed not only the decrease in latency but also disturbances of behaviors after receiving thermal pain. The plantar test is a model of acute thermal pain (24); it is interpreted that flinching may occur as a spinal reflex but licking may be produced by the central regulation. Typically, when a nociceptive sensation is strong, the animal shows flinching and licking after paw withdrawal. Thus, the increase in latency (paw withdrawal alone $<$ flinching $<$ licking) observed in LETO rats seems reasonable. On the other hand, no difference in latency among three patterns (paw withdrawal alone, flinching, and licking) in OLETF rats suggested that the interpretation of thermal pain signals in the brain might be disturbed.
The contents of 5-HT and its metabolite 5-HIAA were significantly higher in the hippocampus and cerebral cortex of OLETF than in those of LETO rats, although the 5-HT content alone in the striatum was significantly higher in OLETF than LETO rats. Serotonergic hyperfunction in OLETF rats was also observed in the previous reports by Shimazoe et al. (26, 27 ), although the precise mechanism of the hyperfunction has not been elucidated. Recently, it was reported (28) that microinjection of 5-HT2A receptor antagonist into the dorsal hipppocampal CA1 and dentate gyrus decrease nociceptive behavior, and it was proposed that 5-HT2A receptor-sensitive mechanisms in the hippocampus may play a role in nociception and/or the expression of related behaviors in rats. This report is compatible with our present observation: hyperalgesia and the increase in 5-HT function in the hippocampus of OLETF rats. However, there was also a report that 5-HT facilitates GABAergic neurotransmission in the rat hippocampus (29). GABAergic hyerfunction may predict anti-nociception. On the other hand, 5-HT evokes a biphasic response of pyramidal cells of the rat hippocampal CA1 region, consisting of a hyperpolarization followed by a longer-lasting depolarisation, each mediated by different receptor subtypes $(30,31)$. Therefore, it is inconclusive whether an increase in 5-HT function in the hippocampus of OLETF rats might be responsible for a thermal hyperalgesia, although it is accepted that 5-HT signaling originating from the raphe nucleus projects to the dorsal horn of the spinal cord, which is one of the candidates for the anti-nociceptive pathway $(23,32)$. Unfortunately, we did not measure 5 -HT content in the spinal cord.

There have been reports that systemic administration of the selective serotonin reuptake inhibitor (SSRI) showed an anti-nociceptive effect in mice $(33,34)$. OLETF rats showed increased anxiety $(15,35)$. The emotional factor may be involved in pain sensation (36). Kagamiishi et al. reported (37) that intracerebroventricular administration of corticotropin-releasing factor (CRF) increased 5-HT release in the ventral hippocampus as well as induced anxiety-like behavior. Therefore, it is suggested that 5-HT hyperfunction in the hippocampus and in the cerebral cortex of OLETF rats might be related to regulation of noxious thermal sensation, such as changing the threshold and/or interpretation of the sensation.

It was reported $(38-40)$ that dopaminergic mechanisms were involved in tonic pain and/or hypersensitivity caused by sustained nociception via the $\mathrm{D}_{2}$ receptor, but there has been no report with respect to thermal pain. Moreover, the contents of dopamine and dopamine metabolites did not differ between OLETF 
and LETO rats. Thus, the involvement of dopamine mechanism in thermal hyperalgsia in OLETF rats could be ruled out.

Neither dopamine nor 5-HT differed in any brain region between CCK-AR(-/-) and wild-type mice. It does not seem that absence of CCK-AR is a cause of increase in 5-HT. Moreover, results of the plantar test did not differ among CCK-AR(-/-), CCK-BR(-/-), CCK-AR(-/-)BR(-/-), and wile-type mice. Therefore, the disturbance observed in OLETF rats is not attributable to the lack of CCK-AR, although homeostasis of body temperature in response to changes in ambient temperature $\left(0^{\circ} \mathrm{C}-30^{\circ} \mathrm{C}\right)$ requires CCK-AR (3). That is, it is interpreted that CCK-AR may not be involved in noxious thermal sensation, but important for nonnoxious thermal sensation. OLETF rats have multiple gene abnormalities $(12,41)$, although other than CCK$\mathrm{AR}$, none of these abnormalities has been cloned. Unknown factors might have influenced monoamine contents as well as disturbance of thermal response in OLETF rats.

CCK has been known to interact with opiates (5). We did not measure opiates content in these animals, because the assay system has not been settled in our laboratory. The sensory pathway for transmitting temperature signal from the skin to brain was not declined rather the signal was more speedily transmitted in OLETF rats. Recently, transient receptor potential (TRP) super-families have been reported (42). Following the cloning of TRPV1, which is activated by capsaicin and heat $>43^{\circ} \mathrm{C}$, TRPV2 has been also cloned and is activated by heat $>52^{\circ} \mathrm{C}$ (43). Functions of TRPs should be examined in OLETF rats in the future.

In conclusion, OLETF rats showed hyperalgesia and a peculiar response to thermal pain, and 5-HT function in the brain might have some role in this disturbance.

\section{Acknowledgments}

This study was supported in part by a Grant-in-Aid for Scientific Research (B-15390237, to K.M.); a research grant for Comprehensive Research on Aging and Health (10C-4, to K.M.), and a research grant for Longevity Sciences from the Ministry of Health and Welfare (12-01, to A.F.). The experiments comply with the "Principles of animal care", publication No. 8623, revised 1985 of the National Institute of Health, and also with the current laws of the country in which the experiments were performed.

\section{References}

1 Dockray GJ. Immunochemical evidence of cholecystokinin-like peptide in brain. Nature. 1976;264:568-570.

2 Crawley JN. Cholecystokinin-dopamine interactions. Trend Pharm Sci. 1991;12:232-236.

3 Nomoto S, Ohta M, Kanai S, Yoshida Y, Takiguchi S, Funakoshi A, et al. Absence of the cholecystokinin-A receptor deteriorates homeostasis of body temperature in response to changes in ambient temperature. Am J Physiol: Regul Int 2004;287:R556-R561.

4 Szelényi Z, Barthó L, Székely M, Romanovsky AA. Cholecystokinin octapeptide (CCK-8) injected into a cerebral ventricle induces a fever-like thermoregulatory response mediated by type B CCK-receptors in the rat. Brain Res. 1994;638:69-77.

5 Wank SA. Cholecystokinin receptors (review). Am J Physiol. 1995;269:G628-G646.

6 Hill DR, Campell NJ, Shaw TM, Woodruff GN. Auroradiographic localization and biochemical characterization of peripheral type CCK receptors in rat CNS using highly selective nonpeptide CCK antagonists. J Neurosci. 1987;7:2967-2977.

7 Hill DR, Shaw TN, Graham W, Woodruff GN. Autoradiographic detection of CCK-A receptors in primate brain using ${ }^{125}$ I-Bolton Hunter CCK-8 and ${ }^{3} \mathrm{H}-\mathrm{MK}$ 329. J Neurosci. 1990;10:1070-1081.

8 Honda T, Wada E, Battey JF, Wank SA. Differential gene expression of CCKA and CCKB receptors in the rat brain. Mol Cell Neurosci. 1993;4:143-154.

9 Hughes J, Boden P, Costall B, Domeney A, Kelly E, Horwell DC, et al. Development of a class of selective cholecystokinin type $\mathrm{B}$ receptor antagonists having potent anxiolytic activity. Proc Natl Acad Sci U S A. 1990;87:6728-6732.

10 Miyasaka K, Kanai S, Ohta M, Kawanami T, Kono A, Funakoshi A. Lack of satiety of cholecystokinin (CCK) in a new rat model not expressing the CCK-A receptor gene. Neurosci Lett. 1994;180:143-146.

11 Takiguchi S, Takata Y, Funakoshi A, Miyasaka K, Kataoka K, Fujimura Y, et al. Disrupted cholecystokinin type-A receptor (CCK-AR) gene in OLETF rats. Gene. 1997;197:169-175.

12 Kawano K, Hirashima T, Mori S, Saitoh Y, Kurosumi M, Natori T. Spontaneous long-term hyperglycemic rat with diabetic complications. Diabetes. 1992;41:1422-1428.

13 Takata Y, Takiguchi S, Funakoshi A, Kono A. Gene structure of rat cholecystokinin type-A receptor. Biochem Biophys Res Commun. 1995;213:958-966.

14 Kobayashi S, Ohta M, Miyasaka K, Funakoshi A. Decrease in exploratory behavior in naturally occurring choelcystokinin (CCK) A receptor gene knockout rats. Neurosci Lett. 1996; 214:61-64.

15 Yamamoto Y, Akiyoshi J, Kiyota A, Katsuragi S, Tsutumi T, Isogawa $\mathrm{K}$, et al. Increased anxiety behavior in OLETF rats without cholecystokinin-A receptor. Brain Res Bull. 2000;53: 789-792.

16 Nomoto S, Miyake M, Ohta M, Funakoshi A, Miyasaka K. Impaired learning and memory in OLETF rats without cholecystokinin (CCK)-A receptors. Physiol Behav. 1999;66:869872.

17 Miyasaka K, Funakoshi A. Luminal feedback regulation, monitor peptide, CCK-releasing peptide, and CCK receptors. Pancreas. 1998;16:277-283. 
18 Miyasaka K, Funakoshi A. Cholecystokinin and cholecystokinin receptors, A review article. J Gastroenterol. 2003;38:1-13.

19 Miyasaka K, Ichikawa M, Ohta M, Kanai S, Yoshida Y, Masuda $\mathrm{M}$, et al. Increased energy metabolism and energy turnover in mice lacking cholecystokinin-B receptor. J Nutr. 2002;132:739741.

20 Miyasaka K, Kobayashi S, Ohta M, Kanai S, Yoshida Y, Nagata A, et al. Anxiety-related behaviors in cholecystokinin-A, B, and $\mathrm{AB}$ receptor gene knockout mice in the plus-maze. Neurosci Lett. 2002;335:115-118.

21 Takiguchi S, Suzuki S, Sato Y, Kanai S, Miyasaka K, Jimi A, et al. Role of CCK-A receptor for pancreatic function in mice: A study in CCK-A receptor knockout mice. Pancreas. 2002;24: 276-283.

22 Kurosawa M, Uvnäs-Moberg K, Miyasaka K, Lundeberg T. Interleukin-1 increases activity of the gastric vagal afferent nerve partly via stimulation of type A receptor in anesthetized rats. J Auton Nerv Syst. 1997;62:72-78.

23 Horiuchi T, Ogata T, Morino T, Takebe J, Yamamoto H. Serotonergic signaling inhibits hyperalgesia induced by spinal cord damage. Brain Res. 2003;963:312-320.

24 Hargreaves K, Dubner R, Brown F, Flores C, Joris J. A new and sensitive method for measuring thermal nociception in cutaneous hyperlgesia. Pain. 1988;32:77-88.

25 Gamache P, Ryan E, Svendsen C, Murayama K, Acworth IN. Simultaneous measurement of monoamines, metabolites and amino acids in brain tissue and microdialysis perfusates. J Chromatogr. 1993;614:213-220.

26 Shimazoe T, Maetani M, Nakamura S, Yamanouchi S, Watanabe S, Miyasaka K, et al. Lowered entrainment function in the suprachiasmatic nucleus of Otsuka Long Evans Tokushima Fatty (OLETF) rats. Jpn J Pharmacol. 1999;80:85-88.

27 Shimazoe T, Nakamura S, Kobayashi K, Watanabe S, Miyasaka $\mathrm{K}$, Kono A, et al. Role of 5-HT1B receptors in entrainment disorder of Otsuka Long Evans Tokushima Fatty (OLETF) rats. Neuroscience. 2004;123:201-205.

28 Soleimannejad E, Semnanian S, Fathollahl Y, Naghdl N. Microinjection of ritanserin into the dorsal hippocampal CA1 and dentate gyrus decrease nociceptive behavior in adult male rat. Behav Brain Res. 2006;168:221-225.

29 Shen R, Andrade R. 5-Hydroxytryptamine 2 receptor facilitates GABAergic neurotransmission in rat hippocampus. J Pharm Exp Ther. 1998;285:805-812.

30 Andrade R, Nicoll RA. Pharmacologically distinct actions of serotonin on single pyramidal neurones of the rat hippocampus recorded in vitro. J Physiol. 1987;394:99-124.

31 Normann C, Clark K. Selective modulation of $\mathrm{Ca}^{2+}$ influx pathways by 5 -HT regulates synaptic long-term plasticity in the hippocampus. Brain Res. 2005;1037:187-193.

32 Miura T, Okazaki R, Yoshida H, Namba H, Okai H, Kawamura M. Mechanisms of analgesic action of neurotropin on chronic pain in adjuvant-induced arthritic rat: roles of descending noradrenergic and serotonergic systems. J Pharmacol Sci. 2005;97:429-436.

33 Duman EN, Kesim M, Kadioglu M, Yaris E, Kalyoncu NI, Erciyes N. Possible involvement of opioidergic and serotonergic mechanisms in antinoceceptive effect of paroxetine in acute pain. J Pharmacol Sci. 2004;97:161-165.

34 Kesim M, Duman EN, Kadioglu M, Yaris E, Kalyoncu NI, Erciyes N. The different roles of 5-HT(2) and 5-HT(3) receptors on antinociceptive effect of paroxetine in chemical stimuli in mice. J Pharmacol Sci. 2005;97:61-66.

35 Kobayashi S, Miyasaka K, Funakoshi A. Behavior abnormalities in the OLETF rat. In: Shima K, editor. Obesity and NIDDM: lessons from the OLETF rat. Tokyo: Eslevier; 1999. p. 191-198.

36 Jasmin L, Rabkin SD, Granato A, Boudah A, Ohara PT. Analgesia and hyperalgesia from GABA-mediated modulation of the cerebral cortex. Nature. 2003;424:316-320.

37 Kagamiishi Y, Yamamoto T, Watanabe S. Hippocampal serotonergic system is involved in anxiety-like behavior induced by corticotropin-releasing factor. Brain Res. 2003;991:212-221.

38 Wood PB. Mesolilmbic dopaminergic mechanisms and pain control. Pain. 2006;120:230-234.

39 Mansikka H, Erbs E, Borrelli E, Pertovaara A. Influence of the dopamine D2 receptor knockout on pain-related behavior in the mouse. Brain Res. 2005:1052:82-87.

40 Takeda R, Ikeda T, Tsuda F, Abe H, Hashiguchi H, Ishida Y, et al. Unilateral lesions of mesostriatal dopaminergic pathway alters the withdrawal response of the rat hindpaw to mechanical stimulation. Neurosci Res. 2005:52:31-36.

41 Takiguchi S, Takata Y, Takahashi N, Kataoka K, Hirashima T, Kawano K, et al. A disrupted cholecystokinin A receptor gene acted synergistically with ODB-1 gene to diabetic in obese rats. Am J Physiol Endocirnol Metab. 1998;274:E265-E270.

42 Caterina MJ, Schumacher MA, Tominaga M, RosenTA, Levine JD, Julius D. The capsaicin receptor: a heat-activated ion channel in the pain pathway. Nature. 1997;389:816-824.

43 Caterina MJ, Rosen TA, Tominaga M, Brake AJ, Julius D. A capsaicin receptor homologue with a high threshold for noxious heat. Nature. 1999;398:436-441. 